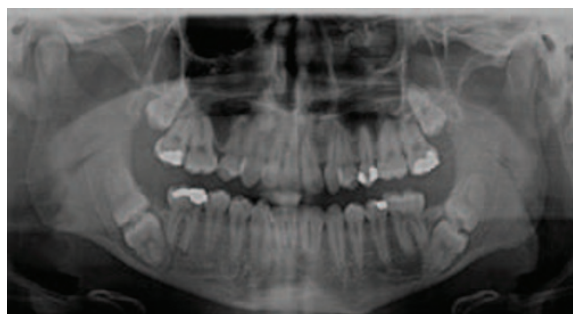

Fig. 2 OPG showing the lower left and right second and third molars impacting into one another

mesial and distal root. The lower right seven is distally impacted in to the mesially impacted lower right eight.

An OPG was taken to fully assess the extent of these impactions (Fig. 2). As can be seen, this patient has both the lower left and right second and third molars impacting into one another. He is also missing the upper lateral incisors.

Upon further questioning the patient said that from time to time he has felt bilateral tingling sensations in his lower lip, which have increased in frequency, and there have been periods when part of his lower lip has gone numb. This could be explained by the proximity of the inferior dental nerve to these impacted teeth and the possible resorption of the bone. The patient has now been referred to the local oral and maxillofacial unit for further investigations and treatment.

In the meantime we have explained to the patient that it is prudent to try and save the lower first molar, and we have commenced root canal therapy on the lower right six and other necessary restorative work.

This case highlights the importance of good radiographic examination to provide the best overall care for patients.

P. Raval, by email

DOI: 10.1038/sj.bdj.2011.343

\section{GIANT CALCULUS}

Sir, we would like to present a very unusual case of giant dental calculus found on the maxilla and mandibular arches leading to facial swelling, lack of labial sealing and oral function impairments. The patient, who was female and 64 years old, was referred to the dental clinic of Varzelandia, Minas Gerais State, Brazil, due to a facial swelling and difficulties closing the lips. Her medical history revealed that she chewed tobacco, was malnourished and at gen- eral clinical examination revealed a noticeable cognitive impairment. It was noted in the history that the lesion had 20 years of progressive growth and the patient had not sought dental evaluation in that time. Due to the lesion, the patient reported severe difficulties socially and in swallowing, eating and talking. General haematological and coagulatory exams, glycaemia and blood pressure tests were normal. Renal dysfunction and diabetes were not shown. At ectoscopy, an evident facial swelling leading to absence of labial sealing and a perceptible oral mass and loss of weight were seen. The clinical oral exam revealed an extensive painful whitish brown mass, with hard consistency, absence of bleeding and detachment from the dental surface, involving the mandibular and maxilla right arches, mimicking a neoplastic lesion (Fig. 1). The teeth had generalised severe periodontal disease, intense amounts of dental calculus and dental mobility and evidence of oral care was absent. With the clinical diagnosis of giant dental calculus, the patient was submitted to mass removal with periodontal curettes and dental extractions were performed due to the periodontal disease. Following this treatment, complete healing was observed. The calcified material was radiographed and submitted to demineralisation and to haematoxylin and eosin staining. The microscopic examination revealed an amorphous basophilic material with mineral crystals (Fig. 2).

Giant dental calculus has been previously described and could be associated with systemic conditions such as poorly controlled Type 2 diabetes. ${ }^{1-2}$ In this case, we removed the incredible size of the calculus and important oral function impairments associated with its presence. Microscopic findings also revealed basophilic material and crystals compatible with calcium phosphates. ${ }^{1}$ Indeed, 'tumoral presentation' can lead to misdiagnosis.

C. Borges Pereira, H. Martelli-Júnior, D. Reis Barbosa Martelli, P. Rogério Ferreti Bonan Brazil

1. Ortega K L, Luiz A C, Martins F M. Calculus or tumour? Br Dent J 2008; 205: 582

2. Minoru M, Akinori I, Hitomi S, Yumiko O, Shun'ichiro N. A case of a giant dental calculus suspected to be a neoplastic lesion. Jpn J Oral Maxillofac Surg 2004; 50: 442-445.

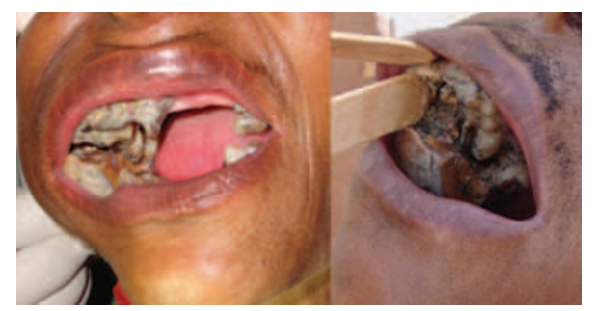

Fig. 1 The extensive whitish-brown mass mimicking a neoplastic lesion

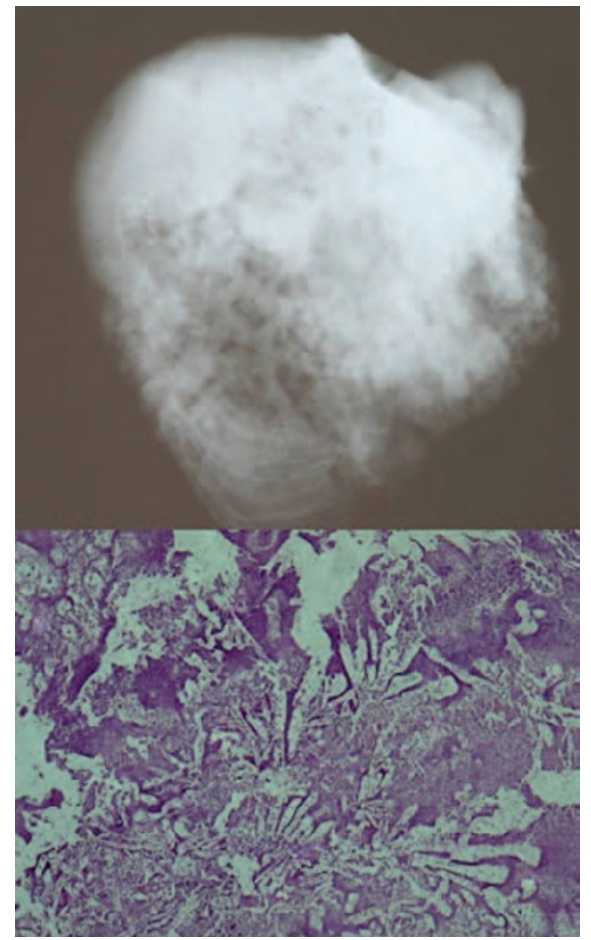

Fig. 2 Radiopaque lesion with dental involvement and pseudolamelar formation. Basophilic material with crystals formation (Haematoxylin and Eosin, low magnification)

DOI: 10.1038/sj.bdj.2011.344

\section{WRONG SIDE SURGERY}

Sir, wrong side surgery is a rare occurrence but can have serious implications. In oral surgery taking a tooth out constitutes $83 \%$ of serious untoward incidents (Beware of wrong tooth extraction; Medical Defence Union, 8 December 2004).

The WHO surgical safety checklist is used in all theatres in hospitals across the country prior to every surgical procedure. In Whipps Cross University Hospital a Surgical Safety Checklist was instituted for all minor oral surgical procedures carried out under local anaesthetic as a measure to improve the standards of patient care. We are delighted to say that we have not had any wrong side surgery since then and audits being carried out every six months have shown $100 \%$ compliance. 
To the best of my knowledge we are the first maxillofacial unit to implement the use of such a checklist and Barts and the London NHS Trust has recently followed our example. I strongly feel that this is a milestone in ensuring patient safety and should be instituted by all maxillofacial units and even dental surgeries to improve quality of care.

S. Duggineni, by email DOI: 10.1038/sj.bdj.2011.345

\section{NOT ESTABLISHED}

Sir, I am writing in response to the letter in the BDJ titled Undermining consent by J. Mew (BDJ 2011; 210: 52).

I would like to say that the so called orthotropics is not an established form of treatment for malocclusion. It is presently neither being taught to postgraduate trainees in orthodontics nor is it recommended as an option of treatment by the NHS. So the question of undermining of consent doesn't arise at all.

Z. Imran, Dundee

DOI: 10.1038/sj.bdj.2011.346

\section{FRAUGHT WITH DANGER}

Sir, I agree with Bob Chate (Dental appliances with inadequate occlusal coverage; $B D J$ 2011; 210: 109-110) that it can be dangerous to use part coverage splints but even the full coverage splints and intrusion wires he recommends have their dangers. A broad band of evidence tells us that in the long-term changing the occlusion usually reduces muscle tone, weakens lip seal, and increases vertical height ${ }^{1,2}$ and an equally broad band suggests that this in turn may reduce arch length, worsen dental crowding and increase the risk of TMD or sleep apnoea. ${ }^{3-6}$ Adjusting the occlusion is fraught with danger.

In one way it is simple: all dentists know that unopposed teeth continue to erupt. Why then don't all patients have full occlusal contact; surely the contact should self correct? The answer is 'not unless the teeth are in contact enough'. The correct balance seems to be four to eight hours of light contact in 24 which will ensure an ideal occlusal height for all humans. ${ }^{7}$ The complex bit is generating enough muscle tone to restore a satisfactory occlusion; there is no other way.
If the muscle tone is weak the teeth over-erupt, premature contacts develop and bite splints fail to work unless they are five or more millimetres high, which risks permanent facial lengthening. As a result of weak muscle tone most civilised humans have their maxilla ten or more millimetres too far down and back from its ideal relationship with the cranial vault. If this is not corrected before the child is 9-years-old they will be stuck with palliative treatment and life-long retention.

\section{J. Mew, by email}

1. Battagel J M. The use of tensor analysis to investigate facial changes in treated Class II division 1 malocclusions. Eur J Orthod 1996; 18: 41-54.

2. Benington P C M, Hunt N P. Masseter muscle volume and craniofacial morphology. Br J Orthod 1994; 21: 407-408.

3. Bondemark L. Does two years nocturnal treatment with a mandibular advancement splint in adult patients with OSAS cause a change in the posture of the mandible? Am J Orthod Dentofacial Orthop 1999: 116: 621-628.

4. Franchi L, Baccetti T, Sacerdoti R, Tollaro I. Dentofacial features associated with crowding of the lower incisors. Eur J Orthod 1997: 19: 570.

5. Iscan H N, Sarisoy L. Comparison of the effects of posterior bite-blocks with different construction bites, on the craniofacial and dentoalveolar structures. Am J Orthod Dentofacial Orthop 1997; 112: 171-178.

6. Almeida F R, Lowe A A, Sung J 0, Tsuiki S, Otsuka R. Long-term sequellae of oral appliance therapy in obstructive sleep apnea patients: Part 1. Cephalometric analysis. Am J Orthod Dentofacial Orthop 2006; 129: 195-204.

7. Lee C F, Proffit W R. The daily rhythm of tooth eruption. Am J Orthod Dentofacial Orthop 1995; 107: $38-47$

DOI: $10.1038 /$ sj.bdj.2011.347

\section{STILL GOING STRONG}

Sir, I enjoyed the recent $B D J$ article on John Ruskin and Alfred James Woodhouse and Mr Bishop's interesting research (BDJ 2011; 210: 179-182).

Then at the end (Dental postscript 2) I was excited (!) to see my old practice mentioned. I wrote a history published in Dental Historian no. 31: November 1996 entitled 'Frederick Bullin (18331904) and White Friars House, Chester'.

The practice is still going strong but I have no access, of course, to any old records - perhaps to see what Mrs La Touche may have been charged!

\section{J. R. Davey, Chester}

DOI: 10.1038/sj.bdj.2011.348

\section{RANCID NUTS}

Sir, I have just read R. Hampton's letter about a patient suffering from pine mouth (BDJ 2011; 210: 151). I have also been suffering from the same thing. I started suffering from a bitter aftertaste while and after eating or drinking. This was really concerning me so I googled 'bitter taste' and was relieved and surprised to find many articles about pine mouth. I had eaten a pine nut salad with pasta and pesto on 13 March at a party I held for my son. As there was some of this salad left over I ate the remainder over the next couple of days. On 15 March I didn't like the taste of the salad so discarded the remains but was left with a slight aftertaste for the rest of the day. The next day just over 24 hours later everything started to taste awful, really bitter. I still had the bitter taste nearly a week later but it is gradually improving. I do not know whether the pine nuts came from China as the dish was ordered from a supermarket catering service. I do feel, however, that the nuts were possibly turning rancid when I ate them after the party date as they were in an oily pesto and parmesan sauce. Unfortunately I think I have overdosed on pine nuts which I will never eat again. It is of concern, as you feel that your system has been temporarily poisoned.

S. Buchanan, by email DOI: 10.1038/sj.bdj.2011.349

\section{PRICELESS}

Sir, an email to my single-handed practice from the CQC (Creating Quality Comedy) regarding the fees ended with the hilarious 'Please ensure this comes to the notice of your Finance Dept'.

Having put up extra shelving to cope with all the files, folders and papers needed to comply with the CQC, we were then doubled up with laughter at 'Think before you print' at the bottom of the email. Priceless!

K. Smith, Quorn

DOI: $10.1038 /$ sj.bdj.2011.350 